\title{
Homophobia in Counselling Practice
}

\author{
Randolph Bowers, ${ }^{1,3}$ David Plummer, ${ }^{2}$ and Victor Minichiello ${ }^{1}$
}

Current attitudes of counselling practitioners towards sexual and gender differences raise the possibility that minority clients may experience re-traumatisation due to in-session expressions of therapist homophobia. This paper explores these issues through a qualitative study that examines client and counsellor narratives on homophobia in counselling. The results describe specific examples of homophobic behaviour by counsellors. While individual examples might appear mundane on the surface, the frameworks they invoke and their pervasiveness constitutes a considerable threat to the counselling relationship. The paper argues that homophobia in counselling practice is a significant issue that requires sensitive, critical and applied analysis that redirects therapeutic efforts in the future.

KEY WORDS: counselling; homophobia; difference; prejudice; bias.

Counselling literature since the 1980 s has attempted to address the specific needs of sexual and gender minority clients in therapy. The literature acknowledges that, while there are many similar issues facing minority people, there are also unique issues that counsellors need to develop awareness of (Appleby \& Anastas, 1998). Gay, lesbian, bisexual and transgendered people come from all parts of society. When stereotypes are highlighted at the expense of acknowledging individuality, retraumatization will result from the insidious effects of social shame and homophobia (Kaufman \& Raphael, 1996).

Across the literature, the term, "homosexuality" is said to inspire strong internal and behavioural responses. For instance, Schwanberg (1990) surveyed attitudes towards homosexuality by reviewing American healthcare literature during the 1980s. The author concluded that prejudice is common among practitioners, and that the AIDS crisis, at least in the early days of the epidemic, increased

\footnotetext{
${ }^{1}$ School of Health, University of New England.

${ }^{2}$ University of the West Indies.

${ }^{3}$ Correspondence should be directed to Randolph Bowers, PhD. School of Health, University of New England, Armidale, New South Wales, Australia 2351; e-mail: rbowers@pobox.une.edu.au.
} 
negative attitudes and prejudice towards gay, lesbian and bisexual clients. A Report of the Gay and Lesbian Medical Association in America (American Counseling Association, 2001, p. 1) states that the medical and psychological impact of homophobia is extensive across various age groups, and can negatively influence the development of self-esteem. The report defined homophobia as "the socialisation of heterosexuals against homosexuals and concomitant conditioning of gays and lesbians against themselves." According to the Medical Association, homophobia "is a legitimate health hazard." Despite the health consequences, addressing homophobic attitudes and practices continues to be a challenge that faces the therapeutic professions.

The literature distinguishes between the attitudes of men versus women toward male or female homosexuality (Kemph \& Kasser, 1996; LaMar \& Kite, 1998). Heterosexual men tend to be more negative toward male homosexuality than heterosexual women, and heterosexual women find lesbian women more discomforting than gay men. Other studies examine the homophobic function of stereotypical attitudes and the social stigma associated with HIV/AIDS, reinforcing the notion that these problems are of great social concern (Luchetta, 1999; Pugh, 1998). Davenport-Hines (1991) suggests that gaining knowledge about the sociohistorical origins of homophobia is a necessary beginning in challenging prejudicial frameworks.

Smith and Gordon (1998) propose that people appear to need a cognitive map that brackets and/or stereotypes gay and lesbian sexualities. Moreover, maintaining cognitive maps may "protect" counselling practitioners by validating their position and reinforcing familiar frameworks that may be inherently prejudicial. Homophobic constructs that underpin stereotypical attitudes may not necessarily be in the counsellor's conscious awareness. Others challenge this view and argue that many conscious attitudes towards homosexuality are sanctioned by everyday mainstream discourse and rendered invisible to the counsellor's analysis by virtue of being so commonplace, and, therefore, normalized (Plummer, 1999). For instance, when looking at attitudes towards homosexuality, De Cecco (1990) and Coleman (1990) suggest that, in mainstream (heterosexual) culture, homosexuality tends to define the gay or lesbian person to the exclusion of other factors. In counselling, when a client discloses sexual orientation, practitioners may foreground sexuality inappropriately, losing a balanced or holistic perspective. The counsellor's countertransference regarding homosexuality, gender and/or sexuality may, during these moments, influence the therapeutic process.

Pardie and Luchetta (1999) propose that heterosexism, like gender bias and racism, is an ideological construct that encodes a person's attitudes along narrow lines. Whether because of fear-based needs for structure, because of learned prejudice, or because of unacknowledged same-sex desire, ideological constructs bind a person's development by disallowing certain perspectives while sanctioning others. Markowitz (1992) suggests that much work needs to be done to raise 
awareness among counselling professionals on issues associated with homophobia. For example, countertransference has been explored in relationship to a therapist's bias towards lesbian clients (Gelso, Fassinger et al., 1995). It is thought that internalised homophobic scripts along with the gender of the counsellor may be important variables in understanding countertransference issues. Mair (2003) explored the narratives of gay men, and suggested that homophobia is a significant problem in clients and their counsellors.

Despite a growing literature on homophobic attitudes, few studies have explored the phenomenological importance of homophobia in counselling practice. The current study aims to address this gap in the literature through conducting in-depth interviews with minority people on their experiences of counselling, and with counsellors on their experiences of working with people who are gay, lesbian, bisexual, and transgendered.

\section{METHODOLOGY}

This study utilized an interpretative and social constructivist approach that sought to explore how participants located their experience of counselling in relation to issues associated with minority identity. From this theoretical perspective the authors began with the premise that people both experience reality and shape reality according to the way meaning is constructed around that reality. For these reasons, the study gathered data in order to better understand the construction of these issues from the perspective of participants.

Within this design, the researchers acknowledge that interpretation of social interactions and data is a necessary component of the research process. Our approach to studying homophobia was fluid and a source of rigorous debate, and began as only a tentative proposition and with great scepticism amongst some of the research team during the first half of this study. However, as evidence from the data continued to emerge throughout the study, a logical and systematic analysis suggested that homophobia was a phenomenon that best described experiences of bias, prejudice and discrimination in everyday life and in counselling.

To further ensure a rigorous design, interviews were structured in a way that information relating to homophobia was unsolicited and the term "homophobia" was not used by the researchers and was not contained in the Participant Information Sheet where the project was simply entitled, "Constructing Counselling Awareness." If and when the term "homophobia" was used by participants, the interviewer inquired by asking open-ended questions that encouraged the participant to describe their experiences further. However, in many instances participants did not specifically label their experiences as "homophobic." Rather, many participants described social interactions that appeared directly linked to their sexual and/or gender identity and that were in some manner difficult, traumatic, and that appeared to increase their sense of social isolation. While the topic of homophobia 
was researched in the literature throughout this study, these themes were largely "suspended" when it came to gathering data from participants on their experiences of counselling. The intention was to offer participants a forum to discuss any issues related to their past counselling interactions. Following on the strength of homophobia as the predominant theme in the data, we have come to affirm that, like sexism, racism, and other "isms," homophobia deserves greater pubic attention in published literature and in research.

The project used theoretical sampling, and began with a sampling frame that identified only that participants would be adults 18 or over, from rural and urban areas, clients and counsellors, and that they would be (in the case of clients and possibly counsellors) gay male, lesbian female, bisexual,transgender, and (in the case of counsellors, likely) heterosexual.

Thirty-four adult participants were interviewed, consisting of 18 clients and 16 counsellors. Client's experiences of counselling varied from single sessions to lengthy therapeutic relationships that spanned several years. Counsellor status varied from new practitioners to senior practitioners, and spanned from professionals with specialization in sexual and gender minority issues to counsellors who had very little experience in the area. Several people had overlapping client/counsellor identities. Interview duration was between one and three hours and total recorded interviewed time is estimated at 56 hours. Interviews were audiotaped. The three open-ended funnel questions used in all interviews were (i) Can you tell me a bit about yourself and how you came to be where you are now? (ii) Tell me a bit about your experiences of (a) counselling, or (b) working with gay, lesbian, bisexual and transgendered clients and, (iii) If you could speak directly to counsellors, what would you tell them that you most want them to know about working with gay and lesbian clients? The interviewer then asked probing questions to follow up lines of inquiry arising from the participants' responses.

The participants were recruited through three methods: by snowball referrals, by posting requests for volunteers on community e-mail list servers, and by contacting counsellors through the telephone directory. Client participants comprised four gay, six lesbian, four bisexual and four transgender participants.

Several counsellor participants identified as gay male and bisexual female. No lesbian counsellors were accessed during the study, though one client who identified as lesbian was a social worker and another who identified as bisexual and "polyamorous" worked in sexual health. When the project began, counsellors were chosen based on their expertise in sexual and gender counselling. It was felt that hearing their perspectives may help the project focus on relevant issues. Later, counsellors who had no experience in the field were sought out to offer a contrast. The counselling practitioners included psychologists, clinical psychologists, clinical social workers, health workers who also worked as counsellors, private practitioners, ministers of religion, alternative practitioners, and counsellors in several fields including individual, couple and family work. 
Interview data were transcribed and coded according to whatever content was apparent in the text. From this simple coding process, each interview was sorted, and each self-apparent code was built upon, and over 800 codes were sorted. This laborious process was facilitated by using a qualitative data analysis programme (Qualitative Research Solutions, 1997). When one code logically combined with another code, a category was developed. Each stage of the process was documented by analytical memos that expressed the rationale for grouping together persistent codes into categories that were identified by a dominant idea.

As categories were clarified throughout the coding process, they were subsumed into larger thematic groups. Client and counsellor data were coded according to themes that emerged across the complete sample, with an emphasis on client-initiated themes. Themes related to homophobia that were documented fell into three areas of experience: (i) family, school, community and religious; (ii) healing from homophobia; and (iii) counselling. Several themes were excluded because of resource limitations; for instance, medical and psychological issues associated with gender reassignment. The following section discusses themes related to homophobia in counselling.

\section{ANALYSIS OF DATA}

\section{A Subtle and Complex Landscape}

It might be thought that "homophobia" is expressed by overt and even violent behaviour, such as gay bashing. While this may be true, the data below suggest a much more subtle and complex landscape of social interactions is taking place between counsellors and clients. This landscape appears to involve the subtle and varied ways that counsellors' perspectives (which may include lack of knowledge, assumptions, bias, and/or prejudice) and their approach to therapy (which may include a range of "inappropriate" behaviours and responses for the client's particular situation) impact on the client and are read as unhelpful and/or homophobic. More often, different types of inadequacies will overlap so that, for instance, a certain lack of knowledge and awareness may be combined with a degree of assumptions, which may or may not include (upon further self reflection) layers of prejudice (that may in many cases be related to past socialization into the gender and sexuality belief systems of one's family of origin and its social milieu).

The following data, whilst not demonstrating all of these points in each instance, collectively demonstrates the logic of the arguments developed. As well, the intention of this section is to introduce and not overshadow the voices of the participants. This reflects closely the data analysis methodology, which sought to reduce subjective interpretation of people's words and allow the interviews in some way to speak for themselves. 
The data presentation begins with the case of "Stephen," a rural based heterosexual counsellor, who works in a school setting. His case illustrates an apparent subtle and complex overlapping of lack of knowledge, assumptions, and perhaps even some level of unacknowledged countertransference and/or prejudice towards minority clients. During the interview Stephen mentioned that it took one of his clients six months to disclose that she was a lesbian. This made the interviewer curious and when asked why it took six months, Stephen said:

It might have been because they weren't ... it might have been because they didn't think it was relevant. It might have been because they wanted to get to know me better... I think the most common answer to that would be, it was just not relevant to the matter that brought them to counselling in the first place. And a lot of people do separate their study or their work.

The interviewer remained silent and the participant continued. It was noticed that his reasons may not account adequately for how his half of the therapeutic relationship influences the level of comfort of sexual and gender minority clients:

I have no doubt that some clients would make the immediate assumption that I am a fairly traditional, conservative sort of 'normal.' I hate the word but... that I'm just an average sort of person and that if they raise a fairly controversial issue with me ... they're not going to quite know how I'm going to react or what I'm going to do with them.

The counsellor appeared to construct where he stood in relation to "traditional" versus "controversial" issues. There is nothing inherently problematic about this framework save that it was curious how his construction appeared to overlook the needs of the client. It may not seem unusual that it would take six months for a client to disclose their sexual orientation to a counsellor, because perhaps her presenting issues were not related to her sexuality. But the discussion of the case suggested that the counsellor missed something during the six month period. Their relationship included discussion of issues related to the student's rural community and family issues, and it seemed evident that the self-presentation of the therapist was somehow involved in not establishing enough trust for the client to disclose a central and important part of her identity when he said:

\footnotetext{
I have things like these posters up here because I have a certain identity and... I want people to try to get to know me as quickly as possible... but I'm not going to change. I don't feel that I need to try and adapt myself to each individual client. I've got to be myself and I've got to be comfortable and I've got to help the clients to get to know me and get comfortable with me.
}

The posters he mentioned were related to his interests in mainstream rock music, and his office looked like any office you may expect to find in a community school or college, except that some counselling offices may or may not display posters about multicultural issues, health issues, or gay and lesbian issues. In these offices the posters may serve to proactively suggest to clients that it is OK to disclose about their identity and issues. His comment that he was not going to change was perhaps his most powerful statement. This combined with 
his assumption that there is no need to adapt to individual clients seems an odd approach for a counsellor to take in a field that demands flexible interpersonal styles and in a practice where he sees a wide range of clientele. The interview that followed reinforced a sense that he assumed and expected that his clients would (or should?) adapt to him. In many ways Stephen seemed to miss the mark with this particular client by uncritically acting on assumptions.

\section{Missing the Mark: Assumptions and Stereotypes}

Jane, a rural based lesbian social worker discussed working as a client with a heterosexual male counselor who identified as heterosexual. Jane was happy he was honest enough to disclose his ignorance of certain issues. Other parts of their relationship greatly troubled Jane:

He said, 'well you'll be getting a lot of support because you're with a female,' and I said, 'well no.' And he said, 'well you'd have a lot of trouble with your family then, you know, here you are stressed and everything and they're not accepting you as in a homosexual relationship.' And I said, 'well no, they are, because I'm still their mum and we always had the grounding, the bonding and everything there.'

Jane was forced to confront his assumptions at every turn and this was exhausting:

He assumed too that within the dynamics of the culture, I was part of . . . . . lesbians would go and protect you. And I said, 'no, we're all individuals and we're all professionals ... And when they get home they are just dog-tired as well, so you haven't got this flock of women nurturing you.'

\section{Jane concluded:}

He sort of had no insight about gay lifestyle and then rather than doing reflective listening and things like that, he made a lot of assumptions that were totally incorrect. I didn't feel as bad as what I had with [my previous] counsellor, but I hadn't moved on very far either because I was dealing with sexuality issues rather than my fears because of the assumptions that he had made. So I was dealing with [his] assumptions and not [my] issues.

The word "assumptions" in such situations can often be read as "stereotypes," and if counsellors relate to stereotypes of a person they are not relating to the person. This identifies an underlying mechanism of homophobia in counselingthat it is possible for a counsellor's unexamined stereotypes of gay and lesbian clients (which are generated in the larger social climate much like sexism and racism) to block effective therapeutic interaction.

Charlie's story shows how counsellors can change these dynamics by facing personal issues through education. He is a heterosexual rural counsellor who came to the discipline later in life. While he candidly disclosed parts of his sexual history during the interview and showed an openness to change, he expressed that gay issues were an area of learning for him. Charlie spoke about how society had 
changed, and that if he just accepted his lack of training in the area he may not work effectively with minority people. So he and his partner (also a counsellor) made a concerted effort to learn about the issues:

We went along to various seminars run by a chap in [rural Australia] who is homosexualhis partner died of AIDS and actually they used to come into our shop back in the 1980 s... Now he does lectures about homosexuality and all the rest of it... so we've made the effort to get the additional education.

During the interview Charlie's ease with the discussion and genuine interest in learning contrasted considerably with Stephen's interview. Cases were discussed where it was assumed the client felt comfortable disclosing their identity, and the counsellor encouraged disclosures through expressing openness, interest, and basic knowledge of the issues.

\section{How Does Homophobia Intrude on Therapy}

Bert, a bisexual male, recalled seeing several counsellors, one of whom identified as lesbian, others appeared to be heterosexual. Bert stated that his heterosexual counsellors would:

... not necessarily be able to relate to the specifics but will give you some general diatribe about what you should do... with all the intentions in the world of helping... just not being able to see the unique perspective of the person.

Bert "spoke" to the heterosexual, middle-aged women, family counsellors he had seen:

I know that you are meaning well and I know you have got a lot of things to say [but] you certainly don't have a certain empathy about [my experience].

While his words were direct and perhaps confronting, he raised an important issue related to many professional counsellors not having enough knowledge, experience, or ability to relate to sexual and gender minority clients. His use of the phrase to be "well meaning" opened a lengthy reflection that was echoed across the data. In a broad sense, when counsellors "mean well" they may be overlooking significant information and may even cause minority clients significant discomfort. From a socially critical perspective, "meaning well" can translate into a veiled attempt to obscure countertransference that may be based in unacknowledged homophobia. To illustrate, Bert stated:

I didn't expect her to be able to relate at all. Maybe... get a vague outline but that really wasn't what I needed ... I certainly didn't begrudge that ... they are the most relevant to have to serve the vast majority of the population ... they certainly listen and they certainly give advice and they have the best intentions in the world...

The question could be asked whether "having the best intentions in the world" might be a way of excusing what may translate into homophobia in counselling 
practice? Consider two levels of homophobia emerging from this analysis. The first is subtle and covert practice (which may be by degrees conscious or unconscious). This is illustrated when counsellors "mean well" but are ill equipped, misinformed and may unintentionally harm clients. Having "good intentions" and "meaning well" not adequate excuses for prejudiced practice (countertransference), even when prejudice "simply" reflects omissions such as ignorance, unpreparedness and use of stereotypes. The second level is more obvious and overt prejudice (which may also be by degrees conscious or unconscious). The problem here is that few people will admit to being prejudiced, but when they do, they often attempt to justify their practices by appealing to homophobic traditions (Noel, 1994; Plummer, 1999, 2000). The next difficulty is deciding what practices ought to be put under "well intentioned" versus "overt prejudice" and how relevant are these categories in any case? Particularly in social climates where "political correctness" prescribes self-censorship of homophobic beliefs and values, the landscape of analysis is more subtle and demanding.

One example of "well meaning" homophobic practice is when a counsellor engages in a protracted assessment, and takes several sessions to get the client's story in relation to understanding their sexuality or gender identity. Jane offered an example of a prolonged assessment:

I couldn't move on very quick because the first three sessions, they were nearly two-hour sessions, was dealing with assumptions of sexuality... I felt like I was dealing with his issues and I couldn't deal with mine.

Claire sought help from many people within various helping professions. She found that no one had the skills and insight to help her in her crisis, and for whatever reasons they all tended to disregard the issues most important to her. She said:

I went to a lot of people for help... [but] did not get it from anybody. Everybody I went to... didn't identify any of my problems. they all treated me like I was just an over imaginative teenager... I didn't need to be given panaceas and ... some of them were 'well meaning' people but they were really dopes...

The practitioners that Claire encountered seemed to have certain traits in common. They were not able to demonstrate empathy or insight and so could not identify her issues. Though Claire's past issues were many and confounded the difficulty of her case, none should have prevented a skilled therapist from building a strong therapeutic alliance with her. Twenty years later she was able to forge a positive relationship with a rural based heterosexual female counsellor. Though she defined this relationship as helpful and constructive, the therapist allegedly exhibited degrees of homophobic behaviour. Claire stated:

She tries very hard to accept that lesbian relationships are equally valid with 'het' relationships. But because it is not a ... let's set up house and have kids, type of variety, she has a bit of difficulty with that... so she tends to not place the same kind of value on it. She doesn't think about it as a relationship, like a sexual, personal, emotional relationship... 
For Claire's counsellor, lesbian relationships were not as valid, legitimate or normal. Again, the counsellor engaged in stereotypes of gender relationships and in the process, devalued the client's experience. Claire knew this dynamic was happening because of the words her counsellor used and did not use:

She has said, 'you two are best friends,' and she would talk about it, 'Oh, when you have a friend.' But when she was talking to me about other clients, she talks about their husband or their wives as their lovers. She doesn't use that terminology with me. Even though she might be talking about my lover, she talks about my 'friend.'

In spite of the counsellor engaging in euphemistic talk, Claire found a basis for respect in the therapeutic alliance:

I now know that this kind of therapeutic relationship is possible... The point is that I've met someone who is prepared to treat me in a way that is meaningful to me... It has given me a bit more faith in the whole process.

\section{Claire described her counsellor's approach:}

My counsellor hasn't insisted on making all the decisions. She has gone through the process with me... and when we haven't had the results that she expected she hasn't blamed me for that, she's looked for another way to get results ... I felt that there isn't something that I have to do right to be able to come back next week, and I haven't had to look after her particularly, to be careful about her feelings ...

Jack, a transgendered person, expressed the relational aspect of therapy in the following way:

Maybe it's about approach or maybe it's about counselling style... but I would prefer if this counsellor would not just listen to what I would say, but actually heard it and tried to understand it, and admitted when she didn't know the answer. That she would allow me to work through some of this stuff... to talk about whatever was going on and to allow me to direct the counselling.

When commenting about the approach of therapists, we acknowledge that poor counselling skills may be a precipitating factor in homophobic practice. This could be the case for beginning or senior counsellors, as higher levels of training do not necessarily correlate with greater sensitivity and/or awareness of minority issues. Jack's comments suggest that regardless of the qualities of the therapist and client, expectations for therapy need to be negotiated.

\section{Acceptance Verses Homophobic Rhetoric}

Jake warns that counsellors may believe they possess acceptance and respect for clients but in reality, communicating those qualities is another matter:

Any course about counselling talks about not being judgmental and respecting other people and blah, blah, blah... There's one thing to be taught that and to believe that you are that, and there's another thing to really be that, to really respect people, to really accept people's choices in life. 
There appears to be a gap between the use of rhetoric and the implementation of inclusive practice. The next case further illustrates this point. Lilliana, a bisexual women, works in sexual health. Homophobic practice is seen by Lilliana as a much more organized system of values held by practitioners. She stated quite clearly that:

There is a very strong culture of heterosexual dominance... and there's this systemic idea that we don't need to learn how to work with gay and lesbian people because there aren't enough of them here, and we've got much more important things to do than worry about poofters and dykes. But that whole thing of heterosexual dominance is ... seeing heterosexuality as the only expression of sexuality.

The social dynamic she discusses appears to subordinate and overlook alternative lifestyles. Regarding the idea that we don't need to learn how to work with minority people because there aren't enough of them, Alex, an urban based heterosexual female counsellor specialising in transgender issues, made this comment:

In the Netherlands, it's [cases of transgender clients] like 1 in 11,000 but in the States it's like 1 in 35,000 . You wonder if there was acceptance ... the others speak up, because they need to hide or they may even suicide... Does 1 in 30,000 justify people knowing about it? I think so. I mean doctors deal with the rare diseases there are one in many thousands, so I don't see why this is not taken seriously.

Alex went on to speak about "gender dysphoria" being a diagnostic category in the DSM IV and she felt that so many practitioners are still ignorant of its dimensions (American Psychiatric Association, 1994). As Alex stated:

[The transgender experience] can't be forgotten by using anti-depressants or any other band aid treatment... It is documented that they must change the body to suit the mind, they can't change their mind to suit the body. It's the only way they can be healthy, functioning individuals...

Transgender experiences require further research and attention. Unfortunately many of the issues raised by transgender participants that were unrelated to homophobia were outside the focus of this study.

\section{The Myth of Neutrality}

Edwina, a heterosexual counsellor, works in a rural setting. She was in her late fifties at the time of the interview. The discussion of her beliefs and values helped to clarify certain ethical boundaries counsellors will face when their beliefs clash with their client's way of life. Though Edwina used the rhetoric of "bracketing" bias, in reality she could not hold her beliefs outside of the counselling process. She began by relating the models that inspired her during her basic training: 
those sorts of counsellor qualities ... I had to learn how to hold back and not say things and how to ask vetted questions... Another influence helping me was the phenomenological approach ... the idea of presuppositionlessness ... to hold in abeyance ... to let the things themselves present themselves to you and to hold your preconceptions in abeyance... some people may think I don't have enough strong opinions myself . . .

It seemed unlikely that Edwina had no strong opinions-she was a senior practitioner and articulated well-developed arguments. Though her statements denied any "definite attitudes" she aligned herself with the liberal traditions of Carl Rogers and the phenomenological tradition.

As analysis progressed, the participant's belief in a counsellor's ability to bracket homophobic bias became implausible, and to the contrary, suggested that an elaborate intellectual rationalisation of bias and prejudicial practice was operating. For example, when Edwina implied that she held her preconceptions "in abeyance," in response to the question "what preconceptions?," she said those that limit acceptance of difference and may increase the likelihood of homophobic practice. On the one hand, it is not unreasonable that counsellors may "hold in abeyance" their preconceptions, as they are expected to do as professionals (American Counselling Association, 1995; Canadian Counselling Association, 1999). On the other hand, though, Edwina's statements might suggest that by rationalising away her inability to withhold homophobic beliefs and by denying her strong opinions, a quite complex mental and/or social "game" was being played out.

When the interviewer inquired, Edwina admitted her strong opinions: "All right, if you press me, I would say I do have a position. But I don't put it forward." She withheld her position, but continued to counsel people if they chose to come to her. Edwina's overt position to her clients was that she was accepting, Rogerian and phenomenological. Her covert position to her clients was that she only "tolerated" sexual difference and did not offer acceptance. She said:

\footnotetext{
The position is that in our society today, I think it's important to tolerate diversity of gender preference and racial origin or whatever... tolerance is highest on my list.
}

It appeared from analysis of several narratives that the nature of "tolerance" is to present a rhetoric of acceptance with underlying and hidden qualifications. Edwina's statements below indicated that tolerance was not actually first on her list of priorities. Put together, the clues suggest a covert and unintended admission of prejudice:

But if I'm upholding values to my children, I will uphold... the value of heterosexual family life... I would still uphold family life. I think if it's your choice to . . be in a samesex relationship and sort of have a family life that way, that is okay. But I think we need as a community... I think we need to, not to promote it, but to tolerate it but not to do things... 


\section{Family Rhetoric and Homophobia}

In Edwina's case, family rhetoric is illustrated. In her framework, offering tolerance to homosexuals is done, ostensibly, to protect the "institution of the family." She also implies that gays and lesbians are anti-family, a position that cannot be supported by reason and research (Benkov, 1994; Green, 1996). In certain cases, prejudice and homophobia appear to be somewhat irrational and based on false assumptions, emotional reactions and stereotypes. From her point of view, supporting lesbian and gay people will undermine the institution of the family. She said:

I can't . . you'll have to help me... I don't want to be seen ... I don't want to sound as though I think one is better than the other. It's like an individual choice. But I think like, I think it's still important somehow to prize... the heterosexual family somehow. Does that make sense?

"Prizing the heterosexual family" sounds like a reasonable proposition. Society can prize many things within a framework of liberal citizenship and equality under the law. But Edwina suggests something more than this. For her, the heterosexual family, itself a label riddled with stereotypes and problematic assumptions, ought to be prized above any other lifestyle and protected as the ideal under the law and through social policy. The key to this argument is that using "the family" as a counterpoint is a false and illogical binary. When the polarisation of "gay versus family" is shed, there is less ammunition and typical views on sexual and gender difference are exposed for what they are-illogical and unfounded prejudice. As a result of her philosophy, Edwina would vote against giving lesbians access to in-vitro fertilisation:

I'm just thinking in terms of how I might vote if I had to choose on these issues in the public arena. What would I choose in relation to certain procedures ... like facilitating the pregnancy of a woman in a lesbian relationship? I think if put to the test, but I'd have to think hard about it, I may well vote against that.

Edwina then spoke of a female client who was seeking counselling around pregnancy issues, she

... wanted to have a child herself without a [male] partner ... I think I just asked questions. I asked questions relating to the rights of the child to have perhaps a father. I would have asked in a very gentle way. But I'm aware that somehow in me, there are these... as you say, there are some views there... there are some things I wouldn't actively advocate. I wouldn't go around saying that it's okay for same-sex couples to be funded from the public purse for facilitating children.

Effectively, the underlying message to her client is that she denies support for the client's need to explore having a child because the women did not have a male partner. 


\section{Counsellor and Client Discomfort}

Many client and counsellor participants suggested that counsellors may not be comfortable in some areas. Alex is a female and bisexual counsellor who worked with transgender clients:

[It is about] being open to hearing anything that they may want to say, especially in areas of intimacy and sexuality and gruelling details you know. I mean, 'he inserted his penis in my new vagina ... this happened' you know. Stuff like that. I'm fine with all of that stuff. I'm not embarrassed about it.

Hlony, a lesbian, found it difficult to speak frankly with her heterosexual counsellor:

I used to find myself that I couldn't tell her a lot of things because I just feel embarrassed. So I wasn't also open about a lot of things because I felt really embarrassed because she was straight. But when I talk to someone who is gay, they can really help me because I'm open, I can just talk about my issues.

Regardless of their sexual or gender identity, counsellors will often be required to "take the first step" in demonstrating comfort. As Hlony said:

Sometimes you need to go down to the nitty gritty of the thing... Because everybody has to be comfortable, both the counsellor and the patient. They've got to both be comfortable.

Jack, a heterosexual therapist, echoed this theme when he said:

For the counsellor, the most important thing is to be comfortable with their own sexuality. I can remember dealing with this guy who... was beginning to come to terms with his sexuality ... and he fell in love with me... what I expressed was that I could hear what he was saying... I could appreciate where he was coming from.

Jack shared that to be open to working with gay men, he needed to first explore his socially learned aversion to homosexuality:

Like the guy who said he loved me, I needed to be able to explore with him what that meant for him and what he was really saying was that 'you've accepted me.' That then meant that I could understand what he meant.

Jack was able to acknowledge the client's feelings and used his interpersonal skills to create an accepting environment where the underlying meanings could be explored.

\section{Homophobia Effects Everyone-we all Lose}

Jack, a heterosexual male counsellor expressed well an obvious point that came from this research:

In some ways both become victims. Homophobia can affect gay people with discrimination, judgements, a whole range of things can occur within the workplace, the social environment, 
the church, and the community. And they are victims of that prejudice. But similarly, the person who is prejudiced is a person who lives in a narrow framework and that has an impact on them and so they become victims from a different perspective...

Using unexamined stereotypes limits our capacity to relate to others. Jack suggests we need to become self-aware:

A friend of mine I've always seen as being very controlled, and a good psychologist in a fairly senior position, and he's come out. But he's jumped ... 180 degrees literally with the explosion. My mind boggles actually, that here's this guy who had had so much suppression for most of his life, he wasn't aware of it ... he was blind as a bat until, I don't know how or why ... His father died, and that gave him the freedom to be himself ... If we suppress things within ourselves, it inhibits our capacity to play and enjoy life.

If we suppress things within ourselves it also likely inhibits our capacity to counsel. So then, homophobia may also include internalized fear surrounding same-sex relationships, suppressed feelings, and unexplored potential in the counsellor (Berkman \& Zinberg, 1997). As the case above illustrates, therapists may be carrying a range of issues stemming from family of origin interactions. Cultural and/or familial assumptions that go unquestioned may also influence a counsellor's values and practice.

\section{CONCLUSION}

As the quotes above suggest, homophobia may be present in many social interactions and may influence the work of counselling practitioners of all sexual and gender identities. Homophobia in counselling is a subtle and complex landscape that may include lack of knowledge, assumptions, bias, and prejudice. Counsellor expressions of homophobic practice in the study have included a wide range of behaviours. These are highlighted in Table I.

From the analysis of data emerged many positive and proactive ways that counsellors can work in this area. Table II pulls suggestions and insights from the interviews discussed above.

Based on our understandings of these insights for improving practice, it is also helpful to establish a basic framework for examining counsellor homophobia. Table III provides key insights from this research that can assist in this endeavour.

While the evidence suggests that homophobia manifests in professionals' attitudes and relationships, the way forward also needs careful consideration. Plummer (1999) encourages the practice of reflexivity when approaching issues around homophobia. Engaging in reflexivity includes being continually open to new experiences and self-awareness. This may be a crucial factor in therapist development when facing issues of homophobia, as reflexivity includes the ability to correct one's perspective through ongoing self-critical analysis.

Though many of the counsellor behaviours that suggest homophobia is present in therapeutic interactions can be addressed by simply doing the opposite, 
Table I. Counsellor Expressions of Homophobia

- Engaging in "well meaning" behaviours that attempt to conceal prejudicial values

- Using stereotypes

- Selective use of language

- Using clients to learn about minority experience

- Inappropriately protracted assessment

- Discounting client's experiences

- Abuse

- Attempting to change sexual orientation

- Supporting systemic attitudes that promote homophobia

- Acting out of incorrect understandings

- Having limiting views of minority people's lives

- Choosing to avoid minorities

- Remaining inflexible in counselling style

- Controlling the course of therapy to suit therapist needs

- Pushing one's assumptions on clients

- Trying to prove broad-mindedness

- Using a rhetoric of tolerance, compassion, and acceptance to mask homophobic values

- Leaving unconscious beliefs unchallenged

- Rationalizing and intellectualizing homophobic beliefs and practices so they appear acceptable and reasonable

- Being uncomfortable with sex talk and sexual feelings in therapy

- Inappropriate boundaries and lacking in personal awareness

Table II. Insights on Addressing Homophobia in Counselling

- Provide support by staying flexible and open to learning

- Establish an environment of safety and comfort for clients

- Attend to assumptions and stereotypes as these create distance and prevent working with real people and their issues

- Generally engage with listening skills, open-ended questions, allowing the client to share their story

- Seek out education on these issues, attend workshops and seminars

- See the unique perspectives of the person

- Demonstrate clearly both empathy and understanding

- Look beyond mainstream culture, and become aware of minority culture, issues, and lifestyles

- Do not use clients to learn-take responsibility for education on these issues

- Be aware of "subtle" uses of language, and realize it is not subtle for many clients

- Be collaborative in exploring mutual goals

- Admit not having answers and/or being ignorant of an issue

- Do not "tolerate" difference, accept and affirm difference — and communicate support and encouragement to clients

- Explore personal cultural traditions and assumptions

- Know yourself-so you can work honestly, transparently, and effectively

- Examine prejudicial beliefs around "family" and ask-what am I afraid of? Why am I getting defensive? What do I have to gain from this stance?

- Acknowledge the social and political landscape

- Be aware of professional and ethical responsibilities to equitable care and consideration

- Be comfortable-find a place of "restless acceptance," or reflexivity, around personal issues, roles, and responsibilities and the client's issues 
Table III. Framework for Examining Counsellor Homophobia

Key insights

- "Bias" against sexual and gender difference surfaces in words or actions a counsellor may see as subtle but the client experiences as blatant.

- Clients (and counsellors) describe negative experiences of counselling that are related to homophobia, and homophobic experiences in counselling are pervasive.

- Both clients and counsellors tend to minimize prejudice by framing it as bias, but clients tend to be more sensitized to homophobic prejudice even when they form rationalizations that minimize its emotional impact.

- Professionals sustain unconscious and conscious cognitive frameworks that strategically isolate prejudiced practice into cloaked categories.

- Counsellors cannot "suspend their bias" (bracket homophobic prejudice) and still work with minority clients without their values coming forward and negatively impacting the counselling process.

\section{Suggestions}

- Counsellor education programs could benefit by inclusion of research and discussion of minority issues at all curricular levels, along with schools of counselling establishing specializations in this area including the support of research chairs in sexual and gender minority studies

- Counsellors should be encouraged to re-educate themselves by attending lectures, workshops, and seminars on these issues

- Professional associations ought to establish professional interest groups within the associations for peer education, research, and dissemination of information

- Greater attention needs to be drawn to homophobia as a serious problem in counselling and other allied health disciplines

- Future research needs to be encouraged that continues to investigate the social, personal, and interpersonal phenomena of homophobia

- Like sexism, gender bias, racism, men's identity issues, women's identity issues, homophobia is an area that will continue to demand extensive social interest and awareness because of its far reaching implications in our understanding of the construction of human gender, sexuality and interpersonal identity

how each person responds in any given situation is far more complex. Rather than addressing specific behaviours, which may be an endless process of elimination, educational programs may be better suited to assisting counsellors to deconstruct a range of attitudes in order to facilitate reflection on underlying beliefs, values, and early experiences of socialization into gender and sexuality roles. Educational programs can benefit by modeling reflexive practices that encourage self-awareness and critical social consciousness. Because the need for awareness of self-in-relation to minority concerns actually precedes the effective use of core conditions and basic counselling skills and because the use of such skills cannot be applied uncritically in a minority context, counselling curriculum requires extensive revision that accounts for issues associated with the social construction of all sexual and gender identities (and cultures) in largely multicultural and complex societies.

Counsellor education programs will benefit by addressing homophobia along with sexual and gender issues from beginning to advanced curricula (Hill, 1998). Counsellor supervision ought to account for the many countertransference issues that arise when approaching practitioners' often unrecognized homophobic 
behaviours (Long, 1996; Russell \& Greenhouse, 1997). Supervisors will, therefore, require education around these issues, and sensitization to their own biases and prejudice. Counselling associations need to encourage higher standards for practice, along with higher expectations for educational qualifications. These standards need to address the prevention of homophobia in counselling.

\section{ACKNOWLEDGMENTS}

The authors acknowledge the helpful contribution of Dr. Margot Schofield in the design of this study, and funding received from the University of New England to support this study.

\section{REFERENCES}

American Counselling Association. (1995). ACA code of ethics and standards of practice. New York, American Counselling Association,

American Counselling Association (2001). Competencies for counselling gay, lesbian, bisexual and transgendered (GLBT) clients. The Association of Gay, Lesbian, and Bisexual Issues in Counselling. http://www.aglbic.org/comptncs.htm. December 20, 01.

American Psychiatric Association. (1994). Diagnostic and statistical manual of mental disorders (4th ed.). Washington, DC, American Psychiatric Association.

Appleby, G., \& Anastas, J. (1998). Not just a passing phase: Social work with gay, lesbian, and bisexual people. New York, Columbia University Press.

Australian Psychological Society. (1990). Code of Ethics. Draft accepted at the Twenty Fourth Annual General Meeting. Victoria, Australian Psychological Society Limited.

Benkov, L. (1994). Reinventing the family: The emerging story of lesbian and gay parents. New York, Crown Publishers.

Berkman, C., \& Zinberg, G. (1997). Homophobia and heterosexism in social workers. Social Work, 42, 319-332.

Blanchard, C., \& Lichtenberg, J. (1998). Counselling psychologists training to deal with their sexual feelings in therapy. The Counselling Psychologist, 26(4), 624-639.

Canadian Counselling Association. (1999). Code of ethics: Canadian Counselling Association. Ottawa, Canadian Counselling Association.

Coleman, E. (1990). Toward a synthetic understanding of sexual orientation. In D. McWhirter, S. Sanders, \& J. Reinich (Eds.), Homosexuality/heterosexuality: Concepts of sexual orientation, (pp. 272-273), New York, Oxford University Press.

De Cecco, J. (1990). Confusing the actor with the act: Muddled notions about homosexuality. Archives of Sexual Behavior, 19, 409-413.

Gelso, C., Fassinger, R., Gomez, M., \& Latts, M. (1995). Countertransference reactions to lesbian clients: The role of homophobia, counsellor gender, and countertransference management. Journal of Counselling Psychology, 42(3), 356-364.

Griffin, G. (1998). Understanding heterosexism: The subtle continuum of homophobia Women and Language. 21, 33-40.

Hill, H. (1998). Overcoming heterosexism and homophobia: Stategies that work (review) Journal of Higher Education. 69(6), 698.

Kaufman, G., \& Raphael, L. (1996). Coming out of shame: Transforming gay and lesbian lives. New York, Doubleday.

Kottler, J., Sexton, T., \& Whiston, S. (1994). The heart of healing: Relationships in therapy. Jossey Bass, San Francisco.

LaMar, L., \& Kite, M. (1998). Sex differences in attitudes toward gay men and lesbians: A multidimensional perspective. The Journal of Sex Research, 35(2), 189-196. 
Lichtenberg, J., \& Kobes, K. (1992). Topic control as relational control and its effects on the outcome of therapy. Psychological Reports, 70, 391-401.

Lichtenberg, J., Wettersten, K., Mull, H., Moberly, R., Merkley, K., \& Corey, A. (1998). Relationship formation and relational control as correlates of psychotherapy quality and outcome. Journal of Counselling Psychology, 45(3), 322-337.

Long, J. (1996). Working with lesbians, gays, and bisexuals: Addressing heterosexism in supervision. Family Process, 35(September), 377-388.

Luchetta, T. (1999). Relationship between homophobia, HIV/AIDS stigma, and HIV/AIDS knowledge. In L. Pardie \& T. Luchetta (Eds)., The construction of attitudes toward lesbians and gay men. (pp. 1-17). New York, Haworth Press.

Mair, D. (2003). Gay men's experiences of therapy. Counselling and Psychotherapy Research, 3(1)3341.

Markowitz, L. (1992). Homosexuality: Are we still in the dark? Confronting homophobia in the therapy room. In The Evolving Therapist: Ten years of The Family Therapy Networker. (Ed.) R. Simon, Washington, DC, Guilford Press.

Noel, L. (1994). Intolerance: A general survey. Montreal, McGill-Queen's University Press.

O’Neill, C., \& Ritter, K. (1992). Coming out within: Stages of spiritual awakening for lesbians and gay men. San Francisco, Harper.

Pardie, L. \& Luchetta, T. (Eds) (1999). The construction of attitudes toward lesbians and gay men. New York, Haworth Press.

Plummer, D. (1999). One of the boys: Masculinity, homophobia and modern manhood, New York, Haworth Press.

Plummer, D. (2000). The quest for modern manhood: Masculine stereotypes, peer culture and the social significance of homophobia. Journal of Adolescence 23(1), 1-9. Available online at http:www.idealibrary.com

Qualitative Solutions and Research. (1997). QSR NUD*IST: Software for qualitative data analysis user guide. Sydney, Qualitative Solutions and Research Pty Ltd.

Russell, G., \& Greenhouse, E. (1997). Homophobia in the supervisory relationship: An invisible intruder. Psychoanalytic Review, 84(1), 27-42.

Schwanberg, S. (1990). Attitudes towards homosexuality in American health care literature 1983-1987. Journal of Homosexuality, 19(3), 117-136.

Smith, M., \& Gordon, R. (1998). Personal need for structure and attitudes toward homosexuality. The Journal of Social Psychology, 138(1), 83-88.

Tracey, T. (1991). The structure of control and influence in counselling and psychotherapy: A comparison of several definitions and measures. Journal of Counselling Psychology, 38(3), 265-278. 